\title{
Business Cycles in Developing Countries
}

\section{Are They Different?}

Rand, John; Tarp, Finn

Published in:

World Development

Publication date:

2002

Citation for published version (APA):

Rand, J., \& Tarp, F. (2002). Business Cycles in Developing Countries: Are They Different? World Development, 30(12). 


\title{
Business Cycles in Developing Countries:
}

\author{
Are They Different?
}

\author{
JOHN RAND and FINN TARP* \\ Institute of Economics, University of Copenhagen, Denmark
}

\begin{abstract}
Summary - This paper demonstrates that developing countries differ considerably from their developed counterparts when focus is on the nature and characteristics of short run macroeconomic fluctuations. Cycles are generally shorter, and the stylized facts of business cycles across countries are more diverse than those of the rather uniform industrialized countries. Supply-side models are generally superior in explaining changes in output, but a "one-size fits all" approach in formulating policy is inappropriate. Our results also illustrate the critical importance of understanding business regularities as a stepping-stone in the process of designing appropriate stabilization policy and macroeconomic management in developing countries.
\end{abstract}

Key words - business cycles, detrending, developing countries, empirical regularities

\footnotetext{
*E-mail: John.Rand@econ.ku.dk and Finn.Tarp@econ.ku.dk. Thanks are due to Mark Watson and Peter F. Christoffersen for providing the Bry and Boschan (1971) routines in GAUSS. Expert advice from Henrik Hansen on econometric issues is acknowledged, and the same goes for the effort of Jesper Linaa in programming a modified version of the procedure in MATLAB. Finally, we would like to express our gratitude for excellent comments from the anonymous referees.
} 


\section{INTRODUCTION}

Macroeconomic stabilization and adjustment became critically important policy objectives in many developing countries in the early 1980s. Since then the design of appropriate domestic economic policies has been in focus in the international development discourse. Paradoxically, only limited efforts have been made to uncover what can be learned from regularities in short run macroeconomic fluctuations in developing nations. Existing literature is almost exclusively concerned with the developed world. Notable exceptions are Agénor, McDermott and Prasad (2000), Bulir and Hamann (2001) and Pallage and Robe (2001). Yet, these contributions are based on an assumption that the length of business cycles is comparable to the duration in industrialized countries. ${ }^{1}$ In this paper, we investigate whether this is a valid starting point. We rely on a sample of 15 developing countries (five in Sub-Saharan Africa, five in Latin America and five in Asia and North Africa), and derive a comprehensive series of stylized facts (covering 19 macroeconomic variables) about business cycles in developing countries. They turn out to be different from those of their developed counterparts in a lot of aspects.

Why is this important? First, the correct duration of macroeconomic fluctuations is critical from an analytical point of view. Stylized facts about business cycles are very sensitive to the length of the cycle used in separating the underlying growth performance from the business cycle component. Second, stylized facts are widely used as benchmark in examining the validity of numerical versions of theoretical models. If the benchmark is incorrectly specified, researchers risk identifying inappropriate causal mechanisms in their attempt at understanding how economies work and respond to shocks. More specifically, it is important whether short-run deviations in output are due to movements in demand or supply. Third, different theoretical models and their adjacent propagation mechanisms often lead to conflicting policy advice. 
Our study shows that supply side models turn out superior in explaining short run fluctuations in output. This suggests that domestic policies geared at stabilizing supply shocks, rather than demand management, should occupy center stage in policy formulation. Our results also confirm that shocks originating in developed countries are important drivers of short run output fluctuations in developing countries. This inter alia implies that policy makers in the donor community and international financial and trade institutions should pay increased attention to the need for international measures to help stabilize against outside shocks.

Following this introduction, Section 2 provides an overview of the methodology used to estimate the duration of the business cycles. Section 3 goes on to document our estimates of duration and turning points of the business cycles and the implication hereof for choosing/estimating optimal smoothing parameters. In Section 4 we derive our new set of stylized facts, and Section 5 concludes.

\section{METHODOLOGY}

In their seminal contribution to the classical business cycle literature, Burns and Mitchell (1946) define business cycles as follows:

Business cycles are a type of fluctuations found in the aggregate economic activity of nations that organize their work mainly in business enterprises: a cycle consists of expansions occurring at about the same time in many economic activities, followed by similarly general recessions, contractions, and revivals which merge into the expansion phase of the next cycle; this sequence of changes is recurrent but not periodic; in duration business cycles vary from more than one year to ten or twelve years; they are not divisible into shorter cycles of similar character with amplitudes approximating their own (Burns and Mitchell, 1946, p. 3). 
Based on this general approach, researchers at the National Bureau of Economic Research (NBER) have for some 75 years worked on the identification of business cycle turning points in a model free environment. ${ }^{2}$ Using monthly series on output, income, employment and trade for an increasing number of sectors, cyclical peaks and troughs have been estimated for each series using a variety of estimation techniques. Supplementing all this with qualitative judgments on the persistence and seriousness of cyclical movements across sectors has formed the basis for the identification of common turning points, including their dates. ${ }^{3}$ It is the latter summary information on the aggregate business cycles that is made publicly available.

The classical methodology of Burns and Mitchell (1946) and the NBER is complex and demanding in terms of analytical capacity. Bry and Boschan (1971) therefore simplified it, and the their new procedure (BB) is based on a single reference series (typically real GDP). The adherent analytical steps and set of decision rules for selecting turning points are summarized in Table 1.

\section{[Table 1 about here]}

All classical approaches to short run macroeconomic fluctuations involve an analysis of total increases/declines in output and/or other indicators over a given time period independent of the underlying nature of the change. In contrast, a competing approach, which we will tentatively refer to as the modern approach, puts focus on the cyclical fluctuations in economic time series data around their long run trends. These short-term fluctuations are often referred to as growth cycles, and they are identified through the application of a trend adjustment procedure, also referred to as filtering. Such detrending may involve loss of information, and ignoring the trend (or the cyclical component) is not consistent with various theoretical models (Stock and Watson, 1999). On the 
other hand, empirical growth cycle analysis is certainly more robust and useful for business cycle management when the underlying trend growth rate in the economy is separated out. ${ }^{4}$

Modern studies of the properties of business cycles have generally relied on linear filters to separate trend and cyclical components. The standard procedure is to detrend the data series using some approximation to an ideal filter and subsequently compute sample second moments based on the cyclical component. Most researchers have used either the Hodrick-Prescott (HP) filter (Hodrick and Prescott, 1997) or the Band-Pass (BP) filter (Baxter and King, 1999). As compared to a standard first differencing filter, the more complex HP-filter has the advantage that it does not amplify high frequency noise. Nevertheless, a drawback is that the HP-filter at the same time allows much of the high frequency noise to be left outside the business cycle frequency band. The low pass BP-filter has been adjusted to take account of this problem, but it has a tendency to underestimate the cyclical component. ${ }^{5}$ In our analysis we therefore use both the HP- and the BP-filters to accommodate the debate between Canova (1998a, 1998b) and Burnside (1998) on appropriate filters.

After the revival of interest in business cycle research following Kydland and Prescott (1982) much mainstream research has relied on an eight-year distinction between business cycles and growth. Moreover, both the HP- and the BP-filters are designed to cut off low frequency cycles of more than 32 quarters duration. While ad hoc this has given rise to the widespread practice of choosing a smoothing parameter $(\lambda)$ for the HP-filter, so $\lambda=1600$ when seasonally adjusted quarterly data are used. ${ }^{6}$ The literature has been somewhat more divided over the issue of how to adjust the filter to other frequencies, and a recent study by Ravn and Uhlig (2002) documents that existing suggestions range between $\lambda=6.25$ and $\lambda=400$ for annual data. Morever, Ravn and Uhlig make the key point that the choice of $\lambda=1600$ for quarterly data in reality reflects a specific definition (or choice) of the length of the business cycle. 
There is limited empirical evidence for the practice of using cycles of eight years when it comes to industrialized countries. This choice may be appropriate in the case of the US, but in other OECD countries six years is likely to be a better estimate (Pedersen, 1998). For developing countries, we know of no study that has tried to estimate the duration of business cycles. Relying on the above smoothing parameters when studying poor countries, may therefore lead to inappropriate conclusions as regards the summary statistics (or stylized facts) that characterize macroeconomic fluctuations. ${ }^{7}$ In the extreme, inappropriate numerical models might be validated and vice versa, depending on the choice of smoothing parameter.

\section{BUSINESS CYCLE DATES AND DURATION}

When estimating the duration of business cycles, their turning points must be identified. For this we apply the BB-procedure, programmed in MATLAB,$^{8}$ on the 15 countries in our sample (Cote d'Ivoire, Malawi, Nigeria, South Africa and Zimbabwe, Chile, Colombia, Mexico, Peru and Uruguay, and India, South Korea, Malaysia, Morocco and Pakistan). ${ }^{9}$ Because of the difficulty of obtaining reliable quarterly GDP data for all of the countries in the sample, we use indexes of industrial production as a proxy for the aggregate business cycle. Agénor, McDermott and Prasad (2000) argue that because output in the industrial sector corresponds roughly to output in the traded goods sector, and is closely related to business cycle shocks for the countries analyzed, this variable is a reasonable proxy for measuring the aggregate business cycle. ${ }^{10}$ The primary data source is the International Monetary Fund (IMF) International Financial Statistics (IFS), where industrial and manufacturing production indices are reported under series number 66. Quarterly data are available for varying time periods in the 15 countries, but the period 1980-99 is well covered across 
countries. Results are summarized in Table 2, including summary data on average expansion and contraction lengths of the business cycle.

[Table 2 about here]

For Latin American countries the average length of the expansion periods is longer than the contraction period, whereas the opposite is characteristic for Asian and North African countries in the sample. It is more difficult to find a pattern in the business cycle duration for Sub-Saharan African countries. Yet, it does appear that the average duration of the business cycle is longer than in the other regions. Generally, it is clear from this analysis that the average length of the business cycle for all developing countries is only between seven and 18 quarters, equivalent to no more than four and a half years. While some variation exists, a period of eight years duration (typically relied on in studies of the US economy) cannot be justified. Taking account of the standard deviation of the results in Table 2, which is in no case more than five quarters, six years is a more appropriate choice of upper limit.

Following Pedersen (2001), we go on to determine the optimal value of the smoothing parameter, $\lambda$, in the HP-filter for each of the 15 countries in the sample. This is done through an iterative process where $\lambda$ is chosen so as to minimize the distorting effect of filtering economic time series with a specific spectral shape. ${ }^{11}$ In our sample, we find that the optimal value of $\lambda$ is between five and 377 when quarterly data are used, as compared to the standard practice of setting $\lambda=1600$. We also configured the BP-filter so as to reflect the appropriate cycle duration. In most cases this implied using a truncation lag parameter of $K=20$.

We now turn to reviewing the actual peaks and troughs for the countries in our sample. ${ }^{12}$ Details are available in Table 2-5, and the interesting questions in the present context are whether (i) the 
timing of recessions and booms are independent across the 15 countries in the sample (i.e., whether there is a common business cycle), and (ii) how business cycles in developing countries compare to cycles in the industrialized countries. Artis, Kontolemis and Osborn (1997) find relatively synchronous peaks/troughs in the years 1973-74, 1979-80 and 1989-90 for G7 and European countries. The first two of these turning points reflect the two international oil crises, and the last episode seems correlated with the collapse of Eastern Europe. Besides these three events not much is apparent in terms of common business cycle features in the industrialized countries. In developing countries the situation differ from region to region.

Table 3 documents peaks and troughs during the period 1980-98 for the five Sub-Saharan African countries. It appears that the second oil crisis and related events affected these countries with a lag as compared to the trough in the industrialized countries. Nevertheless, country specific circumstances appear to have played a role in the more specific timing of the beginning of the recession, and peaks and troughs are not quite as regular as in the Latin American sub-sample, discussed below. ${ }^{13}$ The turning points of the business cycles in Sub-Saharan African countries vary considerably, though a common trough is evident in 1985, reflecting the general economic depression in Africa during the 1980s. In South Africa, recessions got shorter during the period 1980-98, but business cycle features for Nigeria, Zimbabwe and Cote d'Ivoire did not change much during the sample period. Thus, no improvement took place, and in the case of Malawi, the duration of recessions even increased, confirming the troubling difficulties experienced by Malawi (see IMF, 2001b, and Mosley, Harrigan and Toye, 1991).

[Table 3 about here] 
Turning now to the Latin American countries in Table 4, they also experienced a common, lagged trough in 1982, following the second oil crisis. Otherwise the turning points for the individual countries seem country specific. Consistent with the average results in Table 2 the expansion periods are longer for Uruguay, Peru and Mexico during 1980-98 than the contraction periods. However, the recessions clearly got shorter in Mexico during the 1980s and 1990s, as compared with recessions in the 1960s and 1970s. Whether this is due to improved economic policy, exogenous factors, or some combination hereof is an issue that is left for future research, but see for example Giugale, Lafourcade and Nguyen (2001) and Lustig and Ros (1993). Columbia experienced recessions and expansions during 1980-98 of almost identical duration, whereas Chile had much shorter recession periods as compared with earlier decades. This fits well with prior insights about the Chilean economic performance discussed in Solimano (1993) and IMF (2001a). All in all, when the time period for the analysis of Latin American countries is shortened, it becomes clearer that the average expansion periods are longer than the average contraction periods, reflecting improved economic performance in more recent years.

[Table 4 about here]

The business cycles of Asian and North African countries included in Table 5 were influenced by the oil crisis at very different points in time. The relevant dates are almost randomly distributed. It would clearly be interesting to expand the sample to see whether this observation is robust, but the necessary data are not available. In addition, it is only in the case of Malaysia that shorter recession periods were experienced during the period 1980-98 as compared with previous decades.

[Table 5 about here] 
The very frequent and long duration of recession periods in the countries in our sample may appear somewhat surprising as they are generally considered relatively well-managed economies. All in all, it can be concluded that the developing countries in our sample were influenced differently in terms of timing (i.e., with a lag) by the second oil crisis than the industrialized countries. This suggests that business cycles in developing countries may well be as much a result of recessions in the developed world as a consequence of the original international crisis itself. This hypothesis about the vulnerability of developing countries is supported by Kouparitsas (2001). He evaluates the extent to which macroeconomic fluctuations in developing non-oil producing countries are caused by shocks originating in the industrialized countries. His results indicate that fluctuations in output of the industrialized countries may well account for about $70 \%$ of the variation in the consumption of developing countries.

Finally, our results document that the average duration of business cycles in developing countries (generally between 7.7 and 12.0 quarters) is clearly shorter than in the industrialized countries (between 24 and 32 quarters). Korea is an outlier in our sample with a business cycle of 18.1 quarters, but this does not change the general result. Moreover, while few co-movements in terms of common peaks and troughs can be observed in our sample, developing countries typically move relatively quickly from peak to trough and vice-versa. This is costly as documented by Ramey and Ramey (1995) and no doubt reflects the insufficient capacity to counteract exogenous influences, including the limited extent of automatic stabilization. 


\section{4. $\quad$ STYLIZED FACTS}

In this section, we move on to derive the stylized facts for 19 macroeconomic variables that emerge when the shorter business cycle duration established above is taken into account. The detrending procedure described in Section 2 is applied, and the same goes for the information about smoothing parameters in Section 3. For our analysis, we obtained annual macroeconomic data for the period 1970-97 from World Development Indicators (World Bank, 2001), Global Development Finance (World Bank, 2001), International Financial Statistics (IMF, 2001), International Development Statistics (OECD, 2001) and the Global Development Network database from the World Bank WebPages. ${ }^{14}$ All data were subjected to a standard unit root test. Virtually all series were non-stationary, so appropriate filters were applied, and the optimal filters estimated in Section 3 were corrected to fit the change of frequency in the data. In what follows, our results regarding standard deviations and contemporaneous correlations are presented. Tables $6 \mathrm{a}$ and $6 \mathrm{~b}$ to $7 \mathrm{a}$ and $7 \mathrm{~b}$ have the details, where a and b refers to the use of respectively the HP- and the BP-filter in the detrending procedure. The list of variables is shown in the notes to Table 6a, and Appendix Tables A1 and A2 provide further data to allow for comparisons with industrialized countries. ${ }^{15}$

\section{(a) Volatility}

Output in our sample is in general only a little more volatile than in the OECD region. Thus, the magnitude of standard deviations of output in the sample analyzed here is in striking contrast to the volatility reported by Pallage and Robe (2001). Relying on $\lambda$ values in the HP-filter between 10 and 100 for annual data (i.e. cycles of the same duration as in developed countries), they estimate that shocks to poor countries are about six times more severe than shocks to industrialized countries. 
Our results (based on $\lambda$ values around one and shorter cycles) indicate that the volatility of output appears to be only about $15 \%$ to $20 \%$ higher than that of developed countries. This difference evidently highlights that the choice of smoothing parameter is indeed an important one. It can also be noted that on average the volatility of output in Sub-Saharan African countries tends to be somewhat higher than in other developing regions.

Another characteristic in the data is that consumption is generally more volatile than output, with South Africa and India as notable exceptions. This is so both for private and public consumption. This suggests that the consumption smoothing inherent in the permanent income hypothesis appears absent in our sample in contrast to empirical evidence available for the industrialized countries. While not reported in other studies, we believe our result reflects an important empirical fact, namely that consumption smoothening during the business cycle is difficult in a lot of developing countries.

Investment patterns seem more in line with what is documented for industrialized countries, but our sample indicates that private investment tends to be more volatile than public investments. ${ }^{16}$ The standard deviation of savings is generally a little larger in our sample than what can be observed in OCED countries (see Appendix Table A1). Especially Malawi stands out with standard deviations of $41 \%(\mathrm{HP})$ and $43 \%(\mathrm{BP})$, respectively.

Considering trade related indicators, no significant differences in volatility between developing and developed countries can be noted for imports, exports, terms of trade and the real effective exchange rate, and the same goes for money aggregates. For private credit, it even seems as if volatility is on average less in developing countries than in industrialized countries, and the business cycle properties of the inflation rate for the countries in our sample do not differ much from what is observed in developed nations. 
Finally, the volatility of official development assistance (ODA) is high, and this goes for commitments as well as disbursements. This is in accordance with Pallage and Robe (2001), but in contrast to their findings, our study suggests that commitments are not, in general, more volatile than disbursements. We believe this reflects that commitments are in many cases based on country programming with relative stable allocations, as compared to disbursements, which are subject to absorptive capacity and a variety of intricate disbursement constraints on the donor side. We also highlight that ODA as a share of GDP is relatively minor, especially in Latin America, and Asia and North Africa. The balance vis-à-vis foreign direct investment (FDI) has shifted considerably in recent years, and our sample documents that FDI inflows are very volatile. Indeed, they are much more volatile than aid flows. Given the size of FDI flows, their volatility is certainly an issue that seems to deserve much more attention.

[Table $6 \mathrm{a}$ and $6 \mathrm{~b}$ about here]

(b) Cross correlations

In analyzing the cross correlations between GDP and other variables, we follow Agénor, McDermott and Prasad (2000), who define a series as pro-cyclical, a-cyclical, or counter-cyclical depending on whether the contemporaneous correlation coefficient is positive, zero, or negative. In addition, the series is thought of as significantly contemporaneously correlated when $0.26<|\mathrm{X}|<1.00$, where $\mathrm{X}$ represents the cross correlation coefficient between GDP and the other variable involved. 
(i) Consumption, investment and savings

From Table $7 \mathrm{a}$ and $7 \mathrm{~b}$ it can be seen that there is a robust positive relationship between consumption, both total and private, and domestic output in developing countries, except for Nigeria, and the magnitude of the correlations is in line with that observed in OECD. The relationship between public expenditure and GDP often attracts considerable attention, inter alia because of the desire to ensure that fiscal policies help stabilize the economy. We find indications of a significant positive relationship between public expenditure and output for six of the countries in the sample and generally there is no clear evidence of a counter-cyclical role of fiscal policy in the present data. The contemporaneous correlation between private and public consumption is reported in Appendix Table A3. For some countries (Malawi, Zimbabwe, Columbia and Pakistan) private and public consumption appear as substitutes, whereas they are complements in Cote d'Ivoire, Chile, Mexico and Peru.

There is a strong and positive contemporaneous correlation between detrended investment and GDP in almost all the developing countries in the sample. This observation is not different from what is observed in industrialized countries. The only outliers are Malawi and Nigeria, where there is an insignificant negative correlation between investment and output when looking at the HPfiltered time series. The correlations between investment and output peak at time zero for almost all countries in the sample. ${ }^{17}$ This finding is identical to what is observed for the US economy, but in European countries this correlation peaks with a lag. When building applied models, this is critical for the choice of discount rates and demonstrates the importance of deriving stylized facts as argued by Lucas (1981). Private investments also tend to be strongly correlated with output, whereas it is more difficult to interpret the relationship between public investment and GDP. Especially in the Asian and North African sample there seems to be a negative association between these two variables. Appendix Table A3 suggests that private and public investment are substitutes, although 
only three out of the 11 reported negative contemporaneous correlations are significant. Furthermore, savings are in general strongly positively correlated with output. This is as expected. Moreover, the strong investment-savings association seen in developed countries is not as dominant in our sample. Especially Nigeria stands out due to a negative contemporaneous correlation between investment and savings.

(ii) Trade

Imports and output are positively related in most of the sample, especially in the Latin America (Table $7 \mathrm{a}$ and $7 \mathrm{~b}$ ). This reflects that economic activity in small open economies is generally importdependent. With regard to exports the picture is unclear. In many cases, foreign trade would on balance appear to be counter-cyclical, a characteristic also prevalent in developed countries. Exceptions include Nigeria, Zimbabwe and Pakistan, where there are signs of a positive correlation between the trade balance and output. In Nigeria this can be attributed to the substantial significance of oil exports in GDP.

In industrialized countries it is common to find positive correlation between lagged values of the terms of trade index and domestic output. This is not so in our sample. The fact that over half of the correlations in our sample are either insignificant or negative indicates that terms of trade disturbances may not have been quite as an important source behind general output fluctuations as found by Hoffmeister and Roldos (1997) for Asia and Latin America. Looking at Appendix Table A3 it can be seen that the terms of trade index is generally positively correlated with imports and negatively with exports. This observation is not significantly different from what is observed in developed countries.

The interpretation of the unconditional correlation between output and measures of the real effective exchange rate (REER) is complicated. The short run relationship depends crucially on the 
sources of the macroeconomic fluctuations. Nonetheless, unconditional correlations may be useful for two reasons. First, the signs and magnitude of these correlations could give an indication of the types of shocks that have dominated fluctuations over a given period of time. Second, the correlations could help in interpreting the correlation between output and other trade related variables. In our sample, no clear picture emerges when examining the cross correlation between REER and output. It implies that policy analysis related to business cycles should not overemphasize the effects of REER on the economy.

(iii) Monetary aggregates, prices and inflation

Monetary policy is often assigned a key role in stabilization programs in developing countries, and the relationship between monetary variables and the business cycle is a topic of interest. A large literature has evolved around the question whether money causes output, and a positive correlation between money variables and output exists in industrialized countries. However, Agénor, McDermott and Prasad (2000) identify limited evidence for pro-cyclical monetary aggregates in their sample of mainly middle-income countries. In our sample, the correlation between output and M2 is positive for a majority of the 15 countries considered, and this is so, independent of the filter used. A Granger causality test shows some indication of causality going from money to output, but this result is very sensitive to the choice of lags in the Granger causality procedure. All in all, we find little robust evidence for unidirectional Granger causality from M2 to output.

Another monetary aggregate considered here is domestic private sector credit. Equity markets are weakly capitalized in most developing countries, and this is so in particular in Sub-Saharan Africa. Private sector credit is therefore likely to play a critical role in determining investment and overall economic activity. There is some indication of a pro-cyclical relationship between credit and 
output in the sample. The correlations peak as in Agénor, McDermott and Prasad (2000) at a zero lag, maybe indicating that the availability of domestic credit affects activity fairly rapidly. A Granger causality test indicates that it is very difficult to make robust statements as regards the causality between private sector credit and output, as was the case for the other monetary aggregate M2. Furthermore, looking at Appendix Table A3 there seems to be no clear positive relationship between investment and private sector credit. Yet, it is striking that so many countries show significant positive correlations between output and monetary aggregates. It would certainly appear justified to include monetary variables when modeling business cycles in developing countries. Regardless of the Granger causality test the positive association between private sector credit and domestic activity has important implications for the design of stabilization programs. Ignoring this link may exacerbate the output cost of restrictive monetary policy.

A substantial literature documents the counter-cyclical behavior of prices in industrialized countries, and it is typically argued that this negative relationship provides support for a supply driven interpretation of the business cycle, including real business cycle models. Appendix Table A2 confirms these findings. There is a large negative association between CPI and GDP in the five developed countries included. Looking at our developing country sample the general picture is not quite as clear, although seven out of 11 countries reflect significant negative correlation between prices and output. Especially the Asian and North African region deviates from what is observed in industrialized countries. Chadha and Prasad (1994) document that it is equally important to analyze the stylized facts of inflation before jumping to conclusions regarding the selection of appropriate business cycle models. The key finding in their work is that the inflation rate is generally positively correlated with output in developed countries. Demand-driven models may therefore retain credibility even if counter-cyclical behavior of the price level is observed. Turning to our sample, a much clearer result emerges. In 10 out of 11 countries the cyclical patterns of inflation and CPI are 
the same, and in seven of these cases inflation is negatively correlated with output. ${ }^{18}$ This suggests that supply-driven business cycle models are often appropriate in describing cyclical patterns in developing countries. As such, our analysis is in line with the numerical models put forward by Hoffmeister and Roldos (1997) for Asia and Latin America and Hoffmeister, Roldos and Wickman (1997) for Sub-Saharan Africa.

(iv) Aid and foreign direct investment

Also the correlation between Official Development Assistance (commitments and disbursements) and GDP is documented in Table 7a and 7b. Pallage and Robe (2001) and Bulir and Hamann (2001) conclude that for a majority of the counties in their sample, aid is pro-cyclical. It is also argued that the existence of strongly pro-cyclical aid flows underpins the suggestion that aid may be particularly harmful to growth in the African context. The cyclical nature of aid flows is certainly of interest. However, from our analysis, where optimal filters are applied, it appears that there are no countries where aid disbursements are pro-cyclical in a statistically significant manner, and in 10 cases aid appears counter-cyclical (although correlations are generally insignificant). With respect to aid commitments, there are more signs of aid being pro-cyclical, but the general picture remains inconclusive. Moreover, from Appendix Table A3 it can be seen that there is no clear relationship between aid commitments and disbursements. This underlines the critical importance of choosing the appropriate measure when economic analysis of aid issues is carried out. Studies using one measure are not likely to be comparable with studies using the other.

Looking at foreign direct investment (FDI), country specific circumstances are overwhelming, and there is no general relationship between FDI and output. As can be seen from Appendix Table A3, the same goes for FDI and aid inflows. It would therefore appear that the potential for complementarity between these two sets of resource flows is yet to be fully exploited. Finally, our 
data do not support the hypothesis that domestic investments and foreign direct investment are closely associated. All in all, there is no clear cyclical pattern related to foreign aid and investment in our developing countries sample.

[Table $7 \mathrm{a}$ and $7 \mathrm{~b}$ about here]

\section{CONCLUSION}

The design of appropriate stabilization policy in developing countries has attracted a lot of attention during the past two decades, almost to the point that short run macroeconomic stabilization and adjustment became synonymous with economic development. It is therefore surprising that so little attention has so far been paid to understanding the business cycles in third world countries. As argued by Lucas (1981), understanding the characteristics of short run macroeconomic fluctuations should be an important first step in designing appropriate stabilization policies. We therefore carried out an analysis based on a sample of 15 developing countries. It appeared that cycles are definitely shorter than in the developed world, and turning points vary. Shocks originating in the OECD are critically important drivers of short run output fluctuations in developing countries. This inter alia implies that policy makers in the donor community and international financial and trade institutions should pay increased attention to the need for international measures to help stabilize business cycles in poor nations against outside shocks.

The following conclusions also emerge. First, output is more volatile in developing countries than in industrialized nations, but by no more than $15 \%-20 \%$. Consumption is more volatile than output in most of our sample, and this is so for both private and public consumption. Thus, the permanent income hypothesis is not supported by our data. Aid and foreign direct investments are 
highly volatile, and we agree that this might be harmful. However, FDI flows are much more volatile than foreign aid and also much bigger. Stabilizing FDI is therefore essential in modifying business cycle fluctuations.

Second, consumption and investment are strongly pro-cyclical. Non-counter-cyclical government consumption is typical in all regions, so governments seem to have a limited stabilizing role on the economy. Changing this remains a key challenge in spite of the considerable attention paid to this issue over the past decades. Furthermore it is difficult to identify any clear pattern as regards the impact of changes in the terms of trade on business cycles, but it does appear that the terms of trade are not as significant a destabilizing factor as often assumed. Money aggregates are generally pro-cyclical. So even if causality is unclear, the building of business cycle models without attention to monetary variables is likely to miss the target. Consumer prices reflect the countercyclical features observed in the OECD. Furthermore contrary to developed countries the cyclical features of inflation seem to follow CPI. Demand driven models of the business cycle can therefore be ruled out in the majority of our sample. This suggests that domestic policies geared at stabilizing supply shocks, rather than short run demand management, should in many cases occupy center stage in policy formulation related to business cycle issues. Foreign aid shows no signs of being pro-cyclical. The general picture is mixed and it does not seem warranted to conclude that aid exacerbates macroeconomic instability with adjacent welfare costs.

Third, supply shocks are often the main source of short run output fluctuations in developing countries, and supply side models are typically superior in helping to understand business cycle features. We would, however, hesitate to rule out demand driven models a priori. Given the great variety in our data, the choice of model should depend on country specific insights and circumstances. To uncover these characteristics and derive appropriate policy conclusions, country studies and country specific modeling are required. 
In sum, business cycles in developing countries are definitely different. This is so both for duration and turning points as well as in relation to the stylized facts that characterize third world countries.

\section{NOTES}

${ }^{1}$ Agénor, McDermott and Prasad (2000) have 12 developing countries (mainly middle-income countries) in their sample from which stylized facts are derived for 14 indicators. Bulir and Hamann (2001) and Pallage and Robe (2001) have 72 and 63 countries, respectively, in their sample but only consider stylized facts related to foreign aid.

${ }^{2}$ See http://www.nber.org/cycles.html and Mitchell (1927).

${ }^{3}$ A contraction period is defined as the time from peak to trough of a cycle. Similarly, an expansion period is defined as the time between trough and peak.

${ }^{4}$ Stock and Watson (1999, p. 9) illustrate this with reference to post-war Japan, which has experienced very high growth rates and few absolute declines (and thus few classical business cycles). Nevertheless, Japan has experienced various policy relevant growth cycles.

${ }^{5}$ This is done using a twelve quarter centered moving average, where weights are chosen so as to minimize the squared difference between the optimal and the approximate filters, subject to the constraint that the filter has zero gain at frequency zero. See Stock and Watson (1999, p. 12) for a good illustrative description of how the different filters work.

${ }^{6}$ Pedersen (2001) estimate that the actual optimal smoothing parameter for the US lies in the range $1000-1050$ and not 1600 , but the distortionary effects of using 1600 is small.

${ }^{7}$ Choosing a smaller value of the smoothing parameter removes a larger part of the variance of the series since more low frequency movements are filtered away. As a consequence, the standard deviation can be significantly affected. 
The smoothing parameter also affects the computed second moments, implying that it may be important whether business cycles are defined as cycles with a duration of less than eight years or less than six or seven years.

${ }^{8}$ The computer code can be obtained from the authors on request.

${ }^{9}$ The countries from North Africa should clearly not be grouped with Sub-Saharan Africa due to major differences in economic indicators. To facilitate the presentation of our results they have been grouped under the heading of Asia and North Africa.

${ }^{10}$ It can also be noted that the industrial production share of total GDP is more than $20 \%$ for all of the countries analyzed during the period 1980 - 1998 (WDI, 2001), including all of the Sub-Saharan African countries. Except for Nigeria, the manufacturing production share of total GDP is more than $15 \%$ for all countries in the sample. Furthermore, contemporaneous correlations between the industrial production indexes and GDP show a strong and positive association between the two variables for all countries in the sample.

${ }^{11}$ In a recent working paper Marcet and Ravn (2001) propose an interesting and novel method for adjusting the smoothing parameter in the HP-filter, where the filter is interpreted as the solution to a constrained minimization problem. It is left for future research to establish whether it would more appropriate to use this approach when estimating $\lambda$ in a developing country context.

${ }^{12}$ In analyses of the welfare costs of business cycles, the depth of recessions is evidently an important one. In this paper, we focus squarely on business cycle duration due to the importance hereof for estimating stylized facts.

${ }^{13}$ Data do not allow systematic comparison with experiences following the first oil crisis for Sub-Saharan Africa, but scattered observations not reported here seem to indicate that this variability (i.e. the timing of the onset of the recession in individual countries) was even more pronounced in the early 1970 s.

${ }^{14}$ See www.worldbank.org/research/growth/ 
15 In Appendix Tables A1 and A2, the detrending method of Ravn and Uhlig (2002) was used as they argue convincingly that it is necessary to undertake a downward adjustment in the $\lambda$ value for industrialized countries when annual data are used. Pedersen (2001) shows that his approach and the Ravn and Uhlig method are consistent in the case of industrialized countries.

${ }^{16}$ The exact magnitude of the relative volatility depends crucially on the investment measure used.

17 These correlations are not reported in the tables of this paper, but the analysis is available on request.

${ }^{18}$ Unit root tests for inflation indicate that nonstationarity cannot be rejected. Inflation is therefore detrended in the same manner as the rest of the variables.

\section{REFERENCES}

Agénor, P., McDermott, C., and Prasad, E. (2000). Macroeconomic fluctuations in developing countries: some stylized facts. World Bank Economic Review, 14, 251-285.

Artis, M. J., Kontolemis, Z G., and Osborn, D. R. (1997). Classical business cycles for G7 and European countries. Journal of Business, 70, 249-279.

Baxter, M. and King, R. G. (1999). Measuring business cycles: approximate band-pass filters for economic time series. Review of Economics and Statistics, 81, 575-593.

Bry, G and Boschan, C. (1971). Cyclical analysis of time series: selected procedures and computer programs. NBER.

Bulir, A. and Hamann, A. J. (2001). How volatile and unpredictable are aid flows, and what are the policy implications? IMF Working Paper 01/167.

Burns, A. F. and Mitchell, W. C. (1946). Measuring business cycles. NBER

Burnside, C. (1998). Detrending and business cycle facts: A comment. Journal of Monetary Economics, 41, $513-532$. 
Canova, F. (1998a). Detrending and business cycle facts. Journal of Monetary Economics, 41, 475 - 512.

Canova, F. (1998b). Detrending and business cycle facts: A users guide. Journal of Monetary Economics, $41,533-540$.

Chadha, B. and Prasad, E. (1994). Are prices countercyclical? Evidence from the G-7. Journal of Monetary Economics, 34, 239-257.

Danthine, J.P. and Donaldson, J. (1990). Efficiency wages and the Real Business Cycles. European Economic Review, 34, 1275-1301.

Giugale, M. M., Lafourcade, O. and Nguyen, V. H. (ed.) (2001). Mexico: A comprehensive development agenda for the new era. World Bank, Washington D.C.

Global Development Finance (2001), Cd-Rom, World Bank.

Hodrick, R. J. and Prescott, E. C. (1997). Postwar US business cycles: An empirical investigation. Journal of Money, Credit and Banking, 29, 1-16.

Hoffmeister, A. W. and Roldos, J. E. (1997). Are business cycles different in Asia and Latin America? IMF working paper $97 / 9$.

Hoffmeister, A. W., Roldos, J. E. and Wickman, P. (1997). Macroeconomic fluctuations in Sub - Saharan Africa. IMF working paper 97/82.

IMF (2001a). Chile: Selected issues. Washington D.C.

IMF (2001b). Malawi: Selected issues and statistical appendix. Washington D.C.

International Development Statistics (2001), Cd-Rom, OECD.

International Financial Statistics (2001), Cd-Rom, IMF.

Kouparitsas, M. A. (2001). Evidence of the north - south business cycles. Federal Reserve Bank of Chicago Economic Perspectives, 25, 24-45.

Kydland, F. E. and Prescott, E. C. (1982). Time to build and aggregate fluctuations. Econometrica, 50, 1345 $-1369$.

Lucas, R. E. (1981). Studies in business cycle theory. MIT, Cambridge, MA. 
Lustig, N. and Ros, J. (1993). Mexico. Published in: The rocky road to reform, L. Taylor (ed.). MIT, Cambridge, MA.

Marcet, A. and Ravn, M. O. (2001). The HP-filter in cross-country comparisons. FEDEA Working Paper.

Mitchell, W. C. (1927). Business cycles: The problem and its settings. NBER.

Mosley, P., Harrigan, J. and Toye, J. (1991). Aid and Power: Vol. 2: Case studies. Routledge, London and New York

Pallage, S. and Robe, M. A. (2001). Foreign aid and the business cycle. Review of International Economics, 9, 637-668.

Pedersen, T. M. (1998). How long are business cycles? Reconsidering fluctuations and growth. Discussion Paper 24. Institute of Economics, University of Copenhagen.

Pedersen, T. M. (2001). The Hodrick-Prescott filter, the Slutzky effect, and the distortionary effect of filters. Journal of Economic Dynamics and Control, 25, 1081-1101.

Ramey, G. and Ramey, V. A. (1995). Cross-Country Evidence on the Link between Volatility and Growth. American Economic Review, 85, 1138-1151.

Ravn, M. O. and Uhlig, H. (2002). On adjusting the HP-filter for the frequency of observations. Review of Economics and Statistics, 84, 371-376.

Solimano, A. (1993). Chile. Published in: The rocky road to reform, L. Taylor (ed.). MIT, Cambridge, MA.

Stock, J. H. and Watson, M. W. (1999). Business cycle fluctuations in US macroeconomic time series. In Woodford and Taylor (eds.): Handbook of macroeconomics. Amsterdam, Holland.

World Development Indicators (2001). Cd-Rom. World Bank. 


\section{TABLES AND FIGURES}

\section{Table 1. Bry and Boschan (BB) procedure for programmed determination of turning points}

1. Determination of extremes and substitution of values

2. Determination of cycles in twelve month moving average (extremes replaced).

A: Identification of higher (or lower) than five months on either side.

B: Enforcement of alternation of turns by selecting highest of multiple peaks (or lowest of multiple troughs).

3. Determination of corresponding turns in Spencer curve (extremes replaced).

A: Identification of highest (or lowest) value within +/- five months of selected turn in twelve month moving average.

B: Enforcement of minimum cycle duration of fifteen months by eliminating lower peaks and higher troughs of shorter cycles.

4. Determination of corresponding turns in short-term moving average of three to six months, depending on months of cyclical dominance (MCD).

A: Identification of highest (or lowest) value within + /- five months of selected turn in Spencer curve.

5. Determination of turning points in unsmoothed series.

A: Identification of highest (or lowest) value within +/- four months, or MCD term, whichever is larger, of selected turn in short term moving average.

B: Elimination of turns within six months of beginning and end of series.

C: Elimination of peaks (or troughs) at both ends of series which are lower (or higher) than values closer to the end.

D: Elimination of cycles whose duration is less than fifteen months.

E: Elimination of phases whose duration is less than five months.

6. Statement of final turning points.

Source: Bry and Boshan (1971, p. 21). 
Table 2. Duration of the business cycle for 15 developing countries (in quarters)

\begin{tabular}{|c|c|c|c|c|c|}
\hline Region & Country & $\begin{array}{c}\text { Period } \\
(\mathrm{Q}=\text { quarter })\end{array}$ & $\begin{array}{c}\text { Average expansion } \\
\text { length }\end{array}$ & $\begin{array}{c}\text { Average contraction } \\
\text { length }\end{array}$ & $\begin{array}{c}\text { Average length of the } \\
\text { business cycle }\end{array}$ \\
\hline \multirow[t]{5}{*}{ Sub-Saharan Africa } & South Africa & $61, \mathrm{Q} 1-99, \mathrm{Q} 4$ & 5.8 & 5.9 & 11.8 \\
\hline & Malawi & 70,Q1-99,Q4 & 5.9 & 5.4 & 12.0 \\
\hline & Nigeria & 70,Q1-99,Q4 & 4.0 & 5.5 & 9.5 \\
\hline & Cote d'Ivoire & 68,Q1-99,Q4 & 4.8 & 4.8 & 9.7 \\
\hline & Zimbabwe & 78,Q1-98,Q3 & 5.1 & 5.3 & 10.4 \\
\hline \multirow[t]{5}{*}{ Latin America } & Uruguay & 79,Q1-99,Q4 & 4.9 & 4.3 & 9.1 \\
\hline & Columbia & 80,Q1-98,Q4 & 5.0 & 4.7 & 9.7 \\
\hline & Peru & 79,Q1-99,Q4 & 4.6 & 4.3 & 9.4 \\
\hline & Chile & 60,Q1-99,Q4 & 3.7 & 3.8 & 7.8 \\
\hline & Mexico & 60,Q1-99,Q3 & 4.8 & 4.7 & 9.5 \\
\hline \multirow[t]{5}{*}{ Asia and N. Africa } & India & 60,Q1-99,Q4 & 3.1 & 4.7 & 8.1 \\
\hline & Korea & 60,Q1-99,Q4 & 6.3 & 10.4 & 18.1 \\
\hline & Morocco & 60,Q1-99,Q4 & 3.7 & 4.0 & 7.7 \\
\hline & Pakistan & 70,Q3-99,Q4 & 5.4 & 5.8 & 11.2 \\
\hline & Malaysia & 70,Q1-99,Q4 & 4.2 & 4.9 & 9.6 \\
\hline All Countries & All & & 4.8 & 5.2 & 10.2 \\
\hline
\end{tabular}

Table 3. Peaks and troughs for Sub-Saharan African countries 1980-98

\begin{tabular}{|c|c|c|c|c|c|}
\hline & South Africa & Malawi & Nigeria & Cote d'Ivoire & Zimbabwe \\
\hline Peak/Trough & 81,Q4 - 83,Q1 & 80,Q3 - 82,Q1 & 81,Q1 - 83,Q1 & 81,Q1 - 82,Q4 & $82, \mathrm{Q} 2-83, \mathrm{Q} 1$ \\
\hline Peak/Trough & $84, \mathrm{Q} 2-85, \mathrm{Q} 3$ & $83, \mathrm{Q} 3-85, \mathrm{Q} 1$ & $84, \mathrm{Q} 1-85, \mathrm{Q} 2$ & $84, \mathrm{Q} 1-85, \mathrm{Q} 3$ & $84, \mathrm{Q} 1-85, \mathrm{Q} 4$ \\
\hline Peak/Trough & $86, \mathrm{Q} 3-87, \mathrm{Q} 2$ & $86, \mathrm{Q} 3-88, \mathrm{Q} 1$ & 86,Q1 - 86,Q4 & $86, \mathrm{Q} 2-87, \mathrm{Q} 3$ & $86, \mathrm{Q} 3-88, \mathrm{Q} 1$ \\
\hline Peak/Trough & 88,Q1 - 89,Q1 & $89, \mathrm{Q} 3$ - 91,Q1 & $87, \mathrm{Q} 4$ - 90,Q2 & 89,Q1 - 90,Q3 & $89, Q 1-90, Q 1$ \\
\hline Peak/Trough & 90,Q1 - 91,Q1 & 92,Q3 - 94,Q2 & 91,Q2 - 92,Q3 & 92,Q1 - 93,Q3 & 90,Q4 - 93,Q1 \\
\hline Peak/Trough & $92, \mathrm{Q} 4-94, \mathrm{Q} 2$ & 95,Q3 - 97,Q2 & $93, \mathrm{Q} 4$ - 94,Q4 & $94, \mathrm{Q} 4-95, \mathrm{Q} 3$ & $93, \mathrm{Q} 4-95, \mathrm{Q} 1$ \\
\hline Peak/Trough & $95, Q 3-96, Q 4$ & & $95, \mathrm{Q} 4-96, \mathrm{Q} 3$ & $96, \mathrm{Q} 2-97, \mathrm{Q} 3$ & \\
\hline
\end{tabular}

Table 4. Peaks and troughs for Latin American countries 1980-98

\begin{tabular}{|c|c|c|c|c|c|}
\hline & Uruguay & Columbia & Peru & Chile & Mexico \\
\hline Peak/Trough & 80,Q3 - 82,Q1 & $80, \mathrm{Q} 4-82, \mathrm{Q} 1$ & $80, \mathrm{Q} 4-82, \mathrm{Q} 1$ & $80, \mathrm{Q} 4-82, \mathrm{Q} 1$ & 81,Q3 - 83,Q1 \\
\hline Peak/Trough & $83, \mathrm{Q} 4-84, \mathrm{Q} 3$ & $83, \mathrm{Q} 4-85, \mathrm{Q} 1$ & $83, \mathrm{Q} 4-85, \mathrm{Q} 2$ & $83, \mathrm{Q} 2-84, \mathrm{Q} 1$ & $85, \mathrm{Q} 3-86, \mathrm{Q} 3$ \\
\hline Peak/Trough & $85, \mathrm{Q} 3-87, \mathrm{Q} 1$ & 86,Q3 - 88,Q1 & $86, \mathrm{Q} 4-89, \mathrm{Q} 1$ & $85, \mathrm{Q} 3-86, \mathrm{Q} 3$ & 87,Q2 - 88,Q1 \\
\hline Peak/Trough & $88, \mathrm{Q} 4-89, \mathrm{Q} 3$ & 89,Q3 - 90,Q3 & 89,Q4 - 90,Q3 & $87, \mathrm{Q} 2-88, \mathrm{Q} 1$ & $88, \mathrm{Q} 4-89, \mathrm{Q} 3$ \\
\hline Peak/Trough & 90,Q4 - 92,Q1 & 91,Q4 - 93,Q1 & 91,Q2 - 92,Q3 & $88, \mathrm{Q} 4-89, \mathrm{Q} 3$ & 90,Q4 - 91,Q3 \\
\hline Peak/Trough & 92,Q4 - 94,Q1 & 93,Q1 - 95,Q1 & 94,Q2 - 95,Q1 & $90, \mathrm{Q} 2-91, \mathrm{Q} 1$ & 92,Q2 - 93,Q1 \\
\hline Peak/Trough & 94,Q4 - 95,Q3 & $95, \mathrm{Q} 4$ - 96,Q3 & $95, \mathrm{Q} 4-96, \mathrm{Q} 3$ & 91,Q4 - 93,Q1 & 93,Q4 - 94,Q3 \\
\hline Peak/Trough & $96, \mathrm{Q} 4$ - 97,Q3 & & & 94,Q2 - 95,Q3 & \\
\hline
\end{tabular}

Table 5. Peaks and troughs for Asian and North African countries 1980-98

\begin{tabular}{|c|c|c|c|c|c|}
\hline & India & Korea & Morocco & Pakistan & Malaysia \\
\hline Peak/Trough & 80,Q1 - 81,Q2 & $81, \mathrm{Q} 4-85, \mathrm{Q} 1$ & $80, \mathrm{Q} 4-81, \mathrm{Q} 3$ & 80,Q1 - 81,Q3 & $82, \mathrm{Q} 3-83, \mathrm{Q} 4$ \\
\hline Peak/Trough & $82, \mathrm{Q} 1-83, \mathrm{Q} 2$ & $87, \mathrm{Q} 2-88, \mathrm{Q} 2$ & $82, \mathrm{Q} 2-83, \mathrm{Q} 1$ & $82, \mathrm{Q} 2-83, \mathrm{Q} 3$ & $85, \mathrm{Q} 4-87, \mathrm{Q} 1$ \\
\hline Peak/Trough & $84, \mathrm{Q} 1-85, \mathrm{Q} 2$ & 90,Q3 - 92,Q3 & $83, \mathrm{Q} 4-84, \mathrm{Q} 3$ & $85, \mathrm{Q} 1-86, \mathrm{Q} 2$ & 87,Q4 - 89,Q1 \\
\hline Peak/Trough & $86, \mathrm{Q} 1-87, \mathrm{Q} 2$ & 93,Q2 - 94,Q1 & $85, \mathrm{Q} 2-86, \mathrm{Q} 1$ & 87,Q1 - 88,Q3 & 89,Q4 - 91,Q2 \\
\hline Peak/Trough & 88,Q1 - 89,Q2 & 94,Q4 - 98,Q2 & 86,Q4 - 89,Q1 & 90,Q1 - 91,Q3 & $92, \mathrm{Q} 4-94, \mathrm{Q} 4$ \\
\hline Peak/Trough & 90,Q1 - 91,Q2 & & $89, \mathrm{Q} 4$ - 90,Q3 & 93,Q1 - 94,Q3 & 95,Q4 - 97,Q1 \\
\hline Peak/Trough & 92,Q1 - 93,Q2 & & $91, \mathrm{Q} 4-92, \mathrm{Q} 3$ & 96,Q1 - 97,Q3 & \\
\hline Peak/Trough & 94,Q1 - 95,Q1 & & 93,Q4 - 95,Q1 & & \\
\hline Peak/Trough & 96,Q1 - 97,Q3 & & 95,Q4 - 97,Q1 & & \\
\hline
\end{tabular}


Table 6a. Standard deviations for 15 developing countries, HP, percent

\begin{tabular}{|c|c|c|c|c|c|c|c|c|c|c|c|c|c|c|c|c|c|c|c|}
\hline & GDP & $\mathrm{CON}$ & PRC & PUC & INV & PRI & PUI & IMP & EXP & SAV & TOT & RER & INF & CPI & M2 & CRE & FDI & AID & ODA \\
\hline \multicolumn{20}{|c|}{ Sub-Saharan Africa } \\
\hline C. dIvoire & 1.33 & 2.26 & 2.06 & 3.53 & 5.42 & 9.16 & 8.11 & 2.55 & 4.24 & 8.46 & 4.76 & 5.32 & 53.28 & 1.59 & 5.54 & 6.57 & 53.47 & 10.08 & 19.54 \\
\hline Malawi & 2.14 & 2.71 & 4.43 & 3.95 & 12.41 & 28.90 & 10.36 & 6.43 & 5.15 & 41.07 & 3.58 & na & na & na & 3.59 & 5.02 & 346.81 & 8.86 & 18.60 \\
\hline Nigeria & 2.09 & 3.89 & 4.00 & 7.87 & 7.29 & na & na & 4.84 & 6.03 & 8.79 & 9.14 & 7.11 & 31.54 & 3.67 & 5.99 & 8.33 & 46.60 & 11.49 & 20.12 \\
\hline S. Africa & 1.13 & 0.58 & 0.70 & 0.84 & 6.27 & 8.96 & 2.63 & 3.80 & 1.17 & 3.30 & 1.98 & 3.78 & 4.91 & 0.43 & 3.42 & 3.74 & 232.94 & na & na \\
\hline Zimbabwe & 1.68 & 2.12 & 4.37 & 8.22 & 7.33 & na & na & 3.28 & 3.50 & 10.78 & 2.43 & 2.82 & 24.36 & 1.65 & 4.13 & 6.92 & 204.17 & 21.40 & 23.84 \\
\hline \multicolumn{20}{|c|}{ Latin America } \\
\hline Chile & 1.01 & 2.31 & 2.65 & 1.03 & 7.67 & 12.64 & 6.51 & 3.72 & 2.04 & 8.85 & 3.07 & 3.47 & na & na & 4.78 & 5.37 & 50.25 & 50.04 & 7.15 \\
\hline Colombia & 0.40 & 0.40 & 0.81 & 2.49 & 3.47 & 5.50 & 4.20 & 2.78 & 2.64 & 3.06 & 3.89 & 1.75 & 9.59 & 1.05 & 1.98 & 9.39 & 16.04 & 13.79 & 22.46 \\
\hline Mexico & 0.99 & 1.04 & 1.13 & 0.93 & 3.08 & 4.41 & 4.64 & 5.80 & 1.45 & 2.38 & 3.67 & 4.98 & 21.04 & 4.14 & 7.34 & 11.11 & 13.77 & 18.99 & 17.32 \\
\hline Peru & 1.70 & 1.80 & 1.73 & 3.14 & 4.65 & 5.50 & 4.85 & 4.81 & 3.36 & 7.10 & 5.22 & 5.39 & na & na & 8.17 & 8.11 & 78.33 & 9.29 & 10.24 \\
\hline Uruguay & 1.17 & 1.62 & 1.84 & 1.78 & 9.95 & 13.10 & 8.34 & 2.87 & 2.73 & 11.80 & 4.50 & 4.51 & na & na & 5.62 & 8.14 & 264.31 & 17.79 & 34.77 \\
\hline \multicolumn{20}{|c|}{ Asia and North Africa } \\
\hline India & 1.12 & 0.82 & 0.91 & 1.08 & 3.34 & 5.59 & 3.22 & 3.32 & 1.96 & 3.04 & 4.19 & 2.44 & 44.17 & 1.70 & 2.82 & 2.21 & 212.26 & 10.86 & 12.35 \\
\hline Korea & 1.50 & 1.13 & 1.42 & 1.30 & 5.56 & 7.05 & 4.90 & 3.94 & 5.22 & 6.22 & 2.43 & 2.84 & 34.84 & 2.72 & 4.55 & 4.44 & na & 91.68 & 56.14 \\
\hline Malaysia & 0.88 & 1.08 & 1.27 & 1.50 & 3.28 & 5.78 & 4.40 & 3.48 & 2.06 & 5.05 & 2.86 & 1.54 & 31.03 & 0.77 & 1.56 & 5.97 & 11.08 & 19.38 & 33.13 \\
\hline Morocco & 1.16 & 1.37 & 1.56 & 1.50 & 2.31 & 4.93 & 3.82 & 2.29 & 1.71 & 4.11 & 1.25 & 1.47 & 12.97 & 0.61 & 1.67 & 5.99 & 200.74 & 10.45 & 6.15 \\
\hline Pakistan & 0.61 & 1.10 & 1.49 & 3.06 & 1.71 & 6.30 & 2.30 & 4.15 & 4.61 & 8.80 & 4.98 & 1.84 & 14.68 & 0.80 & 3.08 & 3.22 & 42.07 & 11.61 & 7.38 \\
\hline $\begin{array}{l}\text { services, S } \\
\text { Consumer } \\
\text { developme }\end{array}$ & c. & (di & $\mathrm{m}$ & M2 & Hi & de & (t) & 政 & $\overline{\mathrm{C}=\mathrm{R}}$ & 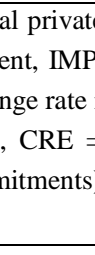 & t & 10 & $C=$ & $\mathrm{g}$ & . & 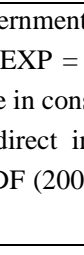 & . & $\begin{array}{l}\text { on, IN } \\
\text { ts of } g \\
\text { s inde } \\
\text { AID }\end{array}$ & $\begin{array}{l}=\text { Real } \\
\text { ds and } \\
\text { CPI }= \\
\text { fficial } \\
\text { (2001) }\end{array}$ \\
\hline
\end{tabular}

Table 6b. Standard deviations for 15 developing countries , BP, percent

\begin{tabular}{|c|c|c|c|c|c|c|c|c|c|c|c|c|c|c|c|c|c|c|c|}
\hline & GDP & $\mathrm{CON}$ & PRC & PUC & INV & PRI & PUI & IMP & EXP & SAV & TOT & RER & INF & CPI & $\mathrm{M} 2$ & CRE & FDI & AID & ODA \\
\hline \multicolumn{20}{|c|}{ Sub-Saharan Africa } \\
\hline C. dIvoire & 1.49 & 2.50 & 2.27 & 3.93 & 5.98 & 10.69 & 8.83 & 2.66 & 4.25 & 9.17 & 5.09 & 5.64 & 59.15 & 1.83 & 5.86 & 6.81 & 58.60 & 10.19 & 20.07 \\
\hline Malawi & 2.17 & 2.68 & 4.42 & 3.81 & 12.86 & 30.20 & 10.40 & 6.57 & 4.69 & 43.48 & 3.23 & na & na & na & 3.71 & 5.60 & 355.05 & 9.02 & 20.20 \\
\hline Nigeria & 2.58 & 4.19 & 4.20 & 8.69 & 7.40 & na & na & 5.12 & 6.52 & 10.49 & 10.32 & 6.57 & 31.83 & 3.44 & 5.96 & 8.43 & 50.54 & 13.58 & 22.07 \\
\hline S. Africa & 1.16 & 0.60 & 0.73 & 0.84 & 6.25 & 9.33 & 2.23 & 3.84 & 1.18 & 2.79 & 1.88 & 3.87 & 4.44 & 0.41 & 3.55 & 3.97 & 257.96 & na & na \\
\hline Zimbabwe & 1.62 & 2.31 & 4.34 & 8.31 & 6.50 & na & na & 3.33 & 3.23 & 9.99 & 1.84 & 3.05 & 26.56 & 1.74 & 4.21 & 7.48 & 222.92 & 20.55 & 22.37 \\
\hline \multicolumn{20}{|c|}{ Latin America } \\
\hline Chile & 1.10 & 2.97 & 3.37 & 1.28 & 8.73 & 15.61 & 6.53 & 3.85 & 2.52 & 12.05 & 3.38 & 2.43 & na & na & 3.95 & 7.00 & 55.55 & 62.19 & 7.47 \\
\hline Colombia & 0.37 & 0.42 & 0.90 & 2.80 & 3.47 & 5.32 & 4.18 & 2.70 & 2.78 & 3.08 & 4.04 & 1.82 & 10.82 & 1.25 & 2.14 & 10.22 & 16.87 & 14.47 & 24.13 \\
\hline Mexico & 1.12 & 1.08 & 1.16 & 1.04 & 3.39 & 4.75 & 4.74 & 5.48 & 1.41 & 2.58 & 4.02 & 4.86 & 21.45 & 4.41 & 8.03 & 11.12 & 13.32 & 21.06 & 16.95 \\
\hline Peru & 1.66 & 1.63 & 1.62 & 2.59 & 3.85 & 4.46 & 5.11 & 4.34 & 3.70 & 7.65 & 5.60 & 6.07 & na & na & 9.30 & 9.31 & 86.63 & 9.46 & 11.12 \\
\hline Uruguay & 1.00 & 1.34 & 1.50 & 2.05 & 9.13 & 11.24 & 7.82 & 2.47 & 2.74 & 11.22 & 4.30 & 4.24 & na & na & 5.76 & 8.63 & 258.83 & 18.78 & 36.12 \\
\hline \multicolumn{20}{|c|}{ Asia and North Africa } \\
\hline India & 1.27 & 0.96 & 1.08 & 1.16 & 3.68 & 6.13 & 3.21 & 3.37 & 2.22 & 3.44 & 4.17 & 2.55 & 48.74 & 1.72 & 3.15 & 2.51 & 233.50 & 11.95 & 13.62 \\
\hline Korea & 1.34 & 1.00 & 1.23 & 1.31 & 4.88 & 6.25 & 4.50 & 3.58 & 4.89 & 5.62 & 2.14 & 2.56 & 31.86 & 2.40 & 3.93 & 3.91 & na & 83.34 & 54.70 \\
\hline Malaysia & 0.93 & 1.14 & 1.20 & 1.72 & 3.50 & 5.75 & 4.93 & 3.73 & 2.26 & 5.63 & 3.16 & 1.38 & 33.23 & 0.78 & 1.75 & 6.22 & 12.21 & 22.46 & 36.92 \\
\hline Morocco & 1.50 & 1.81 & 2.14 & 1.39 & 2.69 & 6.20 & 5.05 & 3.02 & 2.00 & 4.68 & 1.23 & 1.75 & 16.01 & 0.66 & 1.88 & 7.39 & 266.06 & 12.85 & 6.44 \\
\hline Pakistan & 0.72 & 1.14 & 1.56 & 3.36 & 1.66 & 6.92 & 2.35 & 4.49 & 5.25 & 8.46 & 5.29 & 2.31 & 14.77 & 0.82 & 3.31 & 3.08 & 46.34 & 11.91 & 7.66 \\
\hline
\end{tabular}


Table 7a. Cross correlations with output for 15 developing countries, HP

\section{Sub-Saharan Africa}

\begin{tabular}{|c|c|c|c|c|c|c|c|c|c|c|c|c|c|c|c|c|c|c|}
\hline C. dIvoire & 0.82 & 0.78 & 0.78 & 0.38 & 0.06 & 0.42 & 0.21 & -0.53 & 0.11 & 0.45 & -0.13 & -0.11 & -0.32 & 0.01 & -0.14 & 0.06 & -0.38 & -0.11 \\
\hline Malawi & 0.78 & 0.77 & -0.42 & -0.16 & -0.04 & -0.32 & 0.11 & 0.02 & 0.09 & 0.17 & na & na & na & 0.68 & 0.04 & -0.22 & -0.04 & -0.09 \\
\hline Nigeria & -0.00 & 0.04 & -0.14 & -0.05 & na & na & -0.08 & 0.63 & 0.67 & 0.35 & 0.11 & -0.52 & -0.31 & 0.22 & 0.01 & 0.05 & -0.18 & -0.09 \\
\hline S. Africa & 0.76 & 0.78 & 0.15 & 0.88 & 0.92 & 0.08 & 0.93 & -0.12 & 0.48 & 0.29 & -0.04 & -0.25 & -0.35 & 0.15 & 0.16 & 0.17 & na & na \\
\hline Zimbabwe & 0.70 & 0.45 & 0.02 & 0.64 & na & na & 0.05 & 0.58 & 0.70 & -0.53 & -0.66 & -0.44 & -0.75 & 0.29 & -0.09 & 0.25 & 0.00 & 0.06 \\
\hline
\end{tabular}

\section{Latin America}

\begin{tabular}{|c|c|c|c|c|c|c|c|c|c|c|c|c|c|c|c|c|c|c|}
\hline Chile & 0.90 & 0.90 & 0.61 & 0.88 & 0.86 & 0.44 & 0.92 & 0.54 & 0.66 & 0.45 & 0.43 & na & na & 0.34 & 0.53 & 0.35 & -0.16 & 0.18 \\
\hline Colombia & 0.66 & 0.39 & -0.02 & 0.38 & 0.55 & -0.51 & 0.50 & 0.23 & 0.39 & 0.05 & -0.10 & -0.52 & -0.58 & 0.43 & 0.42 & -0.13 & 0.21 & 0.16 \\
\hline Mexico & 0.94 & 0.94 & 0.53 & 0.78 & 0.38 & 0.72 & 0.82 & -0.47 & 0.01 & 0.67 & 0.68 & -0.58 & -0.52 & 0.83 & 0.82 & 0.47 & -0.16 & 0.30 \\
\hline Peru & 0.79 & 0.82 & 0.48 & 0.66 & 0.61 & 0.52 & 0.74 & 0.29 & 0.27 & 0.10 & 0.37 & na & na & 0.19 & 0.16 & 0.09 & -0.19 & 0.02 \\
\hline Uruguay & 0.91 & 0.89 & 0.28 & 0.21 & 0.19 & 0.21 & 0.65 & 0.17 & 0.14 & 0.14 & 0.35 & na & na & 0.34 & 0.12 & 0.22 & 0.16 & 0.17 \\
\hline
\end{tabular}

\section{Asia and North Africa}

\begin{tabular}{|c|c|c|c|c|c|c|c|c|c|c|c|c|c|c|c|c|c|c|}
\hline India & 0.92 & 0.92 & 0.10 & 0.50 & 0.47 & 0.17 & 0.39 & -0.34 & 0.41 & 0.12 & 0.38 & -0.23 & 0.12 & -0.07 & 0.20 & -0.19 & -0.04 & 0.23 \\
\hline Korea & 0.63 & 0.72 & -0.37 & 0.62 & 0.66 & -0.18 & 0.83 & 0.47 & 0.88 & 0.67 & 0.46 & -0.35 & -0.66 & 0.70 & 0.36 & na & -0.13 & 0.06 \\
\hline Malaysia & 0.47 & 0.53 & -0.07 & 0.62 & 0.69 & -0.38 & 0.65 & 0.69 & 0.84 & 0.81 & 0.18 & 0.50 & 0.20 & 0.26 & 0.16 & 0.29 & -0.13 & 0.23 \\
\hline Morocco & 0.84 & 0.81 & 0.40 & 0.49 & 0.54 & -0.10 & 0.18 & 0.18 & 0.47 & -0.11 & 0.11 & 0.19 & 0.10 & 0.07 & -0.21 & -0.19 & -0.00 & -0.08 \\
\hline Pakistan & 0.44 & 0.42 & -0.06 & 0.04 & 0.08 & -0.16 & -0.14 & 0.23 & 0.42 & -0.03 & 0.10 & 0.03 & 0.03 & -0.30 & -0.18 & -0.03 & 0.04 & 0.00 \\
\hline
\end{tabular}

Table 7b. Cross correlations with output for 15 developing countries, BP

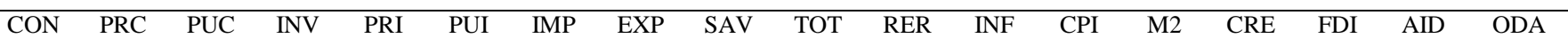

\section{Sub-Saharan Africa}

\begin{tabular}{|c|c|c|c|c|c|c|c|c|c|c|c|c|c|c|c|c|c|c|}
\hline C. dIvoire & 0.85 & 0.81 & 0.82 & 0.37 & 0.06 & 0.40 & 0.21 & -0.51 & 0.15 & 0.42 & -0.16 & -0.09 & -0.30 & -0.03 & -0.20 & 0.07 & -0.35 & -0.09 \\
\hline Malawi & 0.78 & 0.77 & -0.49 & -0.17 & 0.02 & -0.48 & 0.07 & 0.02 & 0.17 & 0.13 & na & na & na & 0.68 & -0.12 & -0.22 & -0.11 & -0.09 \\
\hline Nigeria & -0.03 & 0.01 & -0.14 & 0.03 & na & na & -0.09 & 0.70 & 0.69 & 0.35 & 0.04 & -0.56 & -0.43 & 0.19 & -0.04 & 0.07 & -0.17 & -0.11 \\
\hline S. Africa & 0.75 & 0.79 & 0.02 & 0.84 & 0.90 & -0.14 & 0.92 & -0.29 & 0.32 & 0.17 & 0.05 & -0.46 & -0.51 & 0.18 & 0.18 & 0.18 & na & na \\
\hline Zimbabwe & 0.69 & 0.48 & -0.04 & 0.61 & na & na & -0.05 & 0.43 & 0.69 & -0.30 & -0.71 & -0.39 & -0.71 & 0.29 & -0.02 & 0.02 & -0.22 & -0.11 \\
\hline
\end{tabular}

\section{Latin America}

\begin{tabular}{|c|c|c|c|c|c|c|c|c|c|c|c|c|c|c|c|c|c|}
\hline Chile & 0.95 & 0.95 & 0.80 & 0.94 & 0.92 & 0.49 & 0.94 & 0.58 & 0.78 & 0.69 & 0.46 & na & na & 0.55 & 0.59 & 0.21 & -0.33 \\
\hline Colombia & 0.69 & 0.45 & -0.11 & 0.30 & 0.48 & -0.50 & 0.58 & 0.22 & 0.24 & 0.00 & -0.29 & -0.61 & -0.62 & 0.38 & 0.46 & -0.34 & 0.35 \\
\hline Mexico & 0.94 & 0.94 & 0.52 & 0.78 & 0.36 & 0.71 & 0.79 & -0.23 & 0.22 & 0.64 & 0.67 & -0.56 & -0.45 & 0.80 & 0.78 & 0.50 & -0.22 \\
\hline Peru & 0.75 & 0.78 & 0.34 & 0.58 & 0.47 & 0.49 & 0.60 & 0.49 & 0.41 & 0.22 & 0.23 & na & na & 0.14 & 0.16 & 0.12 & -0.15 \\
\hline Uruguay & 0.90 & 0.86 & 0.34 & 0.32 & 0.27 & 0.24 & 0.58 & 0.14 & 0.35 & 0.28 & 0.12 & na & na & 0.28 & -0.09 & 0.10 & 0.03 \\
\hline
\end{tabular}

\section{Asia and North Africa}

\begin{tabular}{|c|c|c|c|c|c|c|c|c|c|c|c|c|c|c|c|c|c|c|}
\hline India & 0.93 & 0.93 & 0.08 & 0.49 & 0.49 & 0.08 & 0.38 & -0.29 & 0.36 & 0.04 & 0.53 & -0.24 & 0.25 & -0.16 & 0.17 & -0.26 & 0.07 & 0.29 \\
\hline Korea & 0.63 & 0.73 & -0.33 & 0.63 & 0.68 & -0.21 & 0.82 & 0.47 & 0.87 & 0.64 & 0.46 & -0.27 & -0.62 & 0.68 & 0.37 & na & -0.11 & 0.07 \\
\hline Malaysia & 0.40 & 0.50 & -0.03 & 0.64 & 0.73 & -0.33 & 0.68 & 0.75 & 0.81 & 0.75 & 0.05 & 0.41 & 0.33 & 0.25 & 0.10 & 0.34 & -0.06 & 0.26 \\
\hline Morocco & 0.88 & 0.86 & 0.31 & 0.51 & 0.70 & -0.33 & 0.19 & 0.14 & 0.57 & -0.09 & 0.35 & 0.34 & 0.29 & 0.25 & -0.27 & -0.27 & -0.10 & -0.36 \\
\hline Pakistan & 0.46 & 0.41 & 0.03 & 0.14 & 0.13 & -0.10 & -0.10 & 0.32 & 0.48 & -0.10 & 0.22 & 0.03 & 0.10 & -0.37 & -0.22 & -0.02 & 0.09 & 0.02 \\
\hline
\end{tabular}




\section{Appendix}

Appendix Table A1. Standard deviations for 5 Developed Countries, HP, percent

\begin{tabular}{lcccccccccccccccccccc}
\hline & GDP & CON & PRC & PUC & INV & PRI & PUI & IMP & EXP & SAV & TOT & RER & INF & CPI & M2 & CRE & FDI & AID & ODA \\
\hline Canada & 1.56 & 0.85 & 1.22 & 0.88 & 6.40 & Na & na & 4.34 & 3.85 & 6.03 & 2.58 & 3.09 & 46.22 & 1.37 & 4.05 & 5.00 & 71.88 & na & na \\
France & 0.96 & 0.63 & 0.82 & 0.75 & 5.21 & Na & na & 3.83 & 2.28 & 3.92 & 3.10 & 7.60 & 17.80 & 1.31 & na & 25.14 & na & na & na \\
Japan & 1.39 & 1.12 & 1.26 & 1.23 & 4.29 & Na & na & 5.93 & 3.97 & 3.02 & 6.76 & 8.13 & 57.60 & 1.92 & 8.36 & 8.22 & na & na & na \\
UK & 1.72 & 1.34 & 1.88 & 0.91 & 7.41 & Na & na & 3.52 & 2.09 & 5.39 & 2.64 & 7.34 & 30.55 & 2.48 & na & 13.36 & 81.60 & na & na \\
USA & 1.73 & 1.09 & 1.41 & 0.66 & 6.68 & Na & na & 5.37 & 3.90 & 5.28 & 3.11 & na & 25.38 & 1.61 & 1.15 & 2.66 & 32.55 & na & na \\
\hline
\end{tabular}

Notes: See Table 6a. Following Ravn and Uhlig (2002) the smoothing parameter is 1600/256.

Appendix Table A2. Cross Correlations with output for 5 Developed Countries, HP

\begin{tabular}{lcccccccccccccccccc}
\hline & CON & PRC & PUC & INV & PRI & PUI & IMP & EXP & SAV & TOT & RER & INF & CPI & M2 & CRE & FDI & AID & ODA \\
\hline Canada & 0.84 & 0.94 & -0.39 & 0.91 & na & na & 0.81 & 0.69 & 0.90 & -0.34 & -0.32 & -0.11 & -0.73 & -0.19 & 0.21 & 0.38 & na & na \\
France & 0.59 & 0.72 & -0.26 & 0.85 & na & na & 0.81 & 0.78 & 0.90 & 0.46 & 0.09 & 0.30 & -0.44 & na & 0.21 & na & na & na \\
Japan & 0.85 & 0.87 & 0.08 & 0.86 & na & na & 0.68 & -0.13 & 0.87 & 0.27 & -0.02 & 0.27 & -0.68 & 0.25 & 0.21 & na & na & na \\
UK & 0.82 & 0.87 & -0.36 & 0.90 & na & na & 0.84 & 0.62 & 0.80 & 0.33 & 0.13 & -0.08 & -0.73 & na & 0.34 & 0.14 & na & na \\
USA & 0.88 & 0.90 & -0.22 & 0.95 & na & na & 0.87 & 0.39 & 0.93 & 0.55 & na & 0.17 & -0.62 & 0.39 & 0.81 & 0.43 & na & na \\
\hline
\end{tabular}

Notes: See Appendix Table A1.

Appendix Table A3. Cross Correlations between selected variables, corr (xt, yt), HP

\begin{tabular}{|c|c|c|c|c|c|c|c|c|c|c|c|}
\hline & TOT & TOT & RER & RER & PRC & PRI & ODA & AID & INV & INV & INV \\
\hline & IMP & EXP & IMP & EXP & PUC & PUI & AID & FDI & SAV & CRE & FDI \\
\hline \multicolumn{12}{|c|}{ Sub-Saharan Africa } \\
\hline C. dIvoire & 0.51 & -0.43 & 0.09 & -0.29 & 0.78 & -0.16 & 0.65 & 0.29 & 0.35 & -0.35 & -0.14 \\
\hline Malawi & -0.04 & -0.15 & $\mathrm{Na}$ & na & -0.70 & -0.15 & -0.14 & -0.48 & 0.26 & 0.11 & 0.54 \\
\hline Nigeria & 0.25 & 0.28 & 0.30 & 0.09 & 0.20 & na & 0.24 & 0.13 & -0.35 & 0.01 & -0.01 \\
\hline S. Africa & 0.29 & -0.09 & -0.09 & -0.75 & 0.12 & -0.06 & na & na & 0.65 & 0.09 & 0.05 \\
\hline Zimbabwe & -0.24 & -0.89 & -0.30 & -0.24 & -0.75 & na & 0.85 & 0.81 & 0.85 & -0.72 & 0.37 \\
\hline \multicolumn{12}{|c|}{ Latin America } \\
\hline Chile & 0.45 & 0.47 & 0.59 & 0.11 & 0.75 & 0.41 & 0.07 & 0.07 & 0.77 & 0.31 & 0.43 \\
\hline Colombia & 0.23 & -0.11 & -0.01 & -0.69 & -0.77 & -0.40 & 0.03 & -0.22 & 0.27 & 0.38 & 0.16 \\
\hline Mexico & 0.52 & -0.16 & 0.83 & -0.53 & 0.52 & -0.22 & -0.16 & -0.01 & 0.14 & 0.57 & 0.17 \\
\hline Peru & 0.31 & -0.08 & 0.33 & 0.23 & 0.70 & 0.25 & 0.03 & -0.15 & 0.44 & 0.15 & 0.14 \\
\hline Uruguay & 0.50 & -0.34 & 0.18 & -0.22 & 0.18 & -0.10 & 0.18 & 0.32 & 0.91 & -0.21 & -0.05 \\
\hline \multicolumn{12}{|c|}{ Asia and North Africa } \\
\hline India & 0.69 & -0.37 & 0.35 & -0.48 & 0.02 & -0.10 & 0.38 & -0.20 & 0.93 & 0.27 & 0.04 \\
\hline Korea & 0.60 & 0.51 & 0.50 & -0.12 & -0.17 & -0.16 & 0.17 & na & 0.38 & 0.84 & na \\
\hline Malaysia & 0.56 & 0.62 & 0.16 & 0.19 & 0.16 & -0.56 & -0.24 & -0.25 & 0.33 & -0.00 & 0.60 \\
\hline Morocco & 0.16 & -0.49 & 0.04 & -0.11 & 0.19 & -0.21 & 0.54 & 0.00 & 0.44 & 0.14 & 0.03 \\
\hline Pakistan & 0.55 & -0.45 & -0.08 & -0.06 & -0.56 & -0.44 & 0.42 & -0.09 & -0.02 & 0.26 & 0.25 \\
\hline \multicolumn{12}{|c|}{ Industrialized countries } \\
\hline Canada & -0.22 & -0.64 & -0.28 & -0.44 & -0.22 & na & na & na & 0.89 & 0.32 & 0.37 \\
\hline France & 0.65 & 0.40 & 0.28 & -0.19 & 0.03 & na & na & na & 0.88 & 0.14 & na \\
\hline Japan & 0.49 & 0.06 & 0.01 & -0.59 & 0.16 & na & na & na & 0.84 & 0.22 & na \\
\hline UK & 0.37 & 0.28 & 0.07 & 0.02 & -0.24 & na & na & na & 0.76 & 0.16 & 0.05 \\
\hline USA & 0.75 & -0.07 & $\mathrm{Na}$ & na & -0.15 & na & na & na & 0.93 & 0.68 & 0.44 \\
\hline
\end{tabular}

